\title{
Quantitative genetics of aerial dispersal behaviour and life-history traits in Tetranychus urticae
}

\author{
J. LI \& D. C. MARGOLIES* \\ Department of Entomology, Kansas State University, Manhattan, KS 66506-4004, USA
}

\begin{abstract}
Genetic variance and covariance components of aerial dispersal behaviour, fecundity and sex ratio in a population of the two-spotted spider mite, Tetranychus urticae Koch (Acari: Tetranychidae), were estimated by half-sib and full-sib analyses. Additive genetic variation was detected for the dispersal behaviour, but not for fecundity or sex ratio. The observed phenotypic variation and covariation were largely explained by non-additive genetic variation and maternal effect or common environmental variation. The existence of additive genetic variation in aerial dispersal behaviour was likely the result of opposing selection on latency or underlying traits of the behaviour, and not indirect selection on fecundity or sex ratio. Lack of significant genetic correlation between the three traits may indicate that they share few genes or underlying morphological and/or physiological traits in common. The results suggest that aerial dispersal behaviour may be an adaption to unpredictable environments.
\end{abstract}

Keywords: aerial dispersal behaviour, fecundity, genetic correlation, heritability, sex ratio, Tetranychus urticae.

\section{Introduction}

Genetic variance-covariance matrices of fitnessrelated traits partly determine the phenotypes of an organism and impose constraints on life history evolution (Lande, 1982; Travis et al., 1987; Charnov, 1989). Therefore, analysis of genetic variation and covariation in such traits may be the first step to better understanding evolutionary response of the organism to natural selection imposed by the environment. Some lifehistory theories predict that correlations between fitness-related traits are usually negative because of antagonistic pleiotropy (e.g. Rose, 1982). Recent studies on such traits indicate the existence of genetic variation and covariation and support this theory (Rose \& Charlesworth, 1981; Palmer \& Dingle, 1986; Kasule, 1991; Gu \& Danthanarayana, 1992). However, other theories suggest that either positive, negative, or even no correlations may exist (e.g. Houle, 1991), and some studies have found correlations that are positive or zero rather than negative (see Rose et al., 1987). Recent theoretical studies suggest that the existence of low additive genetic variation in life-history traits may

*Correspondence. be inevitable because of their high residual variation (Price \& Schluter, 1991; Houle, 1992). Obviously, more quantitative genetic studies on fitness-related traits are needed to understand the mechanism(s) of life-history evolution. The results of such studies can provide insight into the possible developmental and physiological nature of the relationship among correlated traits and suggest further study that may lead to more understanding of the evolutionary processes and consequences (Scharloo, 1987; Riska, 1989).

Rapid development, high fecundity and survivorship, and the ability to locate better environments by dispersal are thought to be the key elements in the lifehistory of organisms that depend on temporary or ephemeral resources (Southwood, 1962; Parsons, 1983). The two-spotted spider mite, Tetranychus urticae Koch, is a phytophagous species that exploits and appears to be adapted to using a series of temporary hosts. The mite reproduces by arrhenotoky; that is, unfertilized eggs give rise to haploid male offspring, whereas fertilized eggs produce diploid females. Mated females produce both fertilized and unfertilized eggs (Helle, 1967). Under normal conditions, sex ratio is female-biased (usually 3:1) (Krainacker \& Carey, 1990 ), and each mated female may produce 50 or more female offspring, which contribute to a high rate 
of population increase. The two-spotted spider mite is a fast developing organism; at optimum temperature for development (i.e. $30-32^{\circ} \mathrm{C}$ ), the mite can complete a life cycle in about 8-12 days (Jeppson et al., 1975). When the food resource is depleted, mites, predominantly young and mated adult females, in the presence of both light and wind, may disperse aerially on air currents to surrounding areas and build up new colonies rapidly (Smitley \& Kennedy, 1985). These characteristics, combined with high environmental variability generated by frequent disturbance in crop systems, make $T$. urticae a good subject for a study of life-history evolution. The presence research was the first attempt at such a study on this species.

The objectives of this study were to: (i) assess the genetic variation in aerial dispersal behaviour, fecundity, and sex ratio; and (ii) estimate the genetic and phenotypic correlations between these traits. All of these fitness-related traits are likely to be under strong natural selection (Falconer, 1981), which may maintain low genetic variation as measured by the narrow sense heritability. The results of this study may provide insight into the nature of the genetic constraints on the response of these characters to selection and environmental influence on evolutionary process.

\section{Materials and methods}

The two-spotted spider mites used in this study came from a laboratory colony that had been maintained at $\sim 27^{\circ} \mathrm{C}$ on lima bean plants, Phaseolus lunatus L., for about 9 months prior to the experiment. The colony was established with mites collected in April 1991 from vetch plants under peach trees at the Sandhills Experiment Station, Jackson Springs, North Carolina.

\section{Experimental design and procedures}

Experiments were set up as a standard sib design. Offspring sired by the same male constituted a paternal half-sib family, and offspring produced by the same female formed a full-sib family nested within male families. There were 38 males in the experiment, and six females were mated to each male. All measurements of aerial dispersal behaviour, fecundity, and sex ratio were made to their offspring. Newlyemerged virgin females and 1-day-old virgin males were used for successful sib mating. To ensure that mites were virgins prior to mating, male and female quiescent deutonymphs, a stage $\sim 1$ day prior to adult at $27-29^{\circ} \mathrm{C}$, were collected on moderately infested bean leaves from the laboratory population. The collected mites were separated by sex and kept on detached bean leaves, with abaxial surfaces up, pressed on wet cotton in petri dishes. On the emergence of mites into adults, males were placed individually on a detached bean leaf, and six females were provided to each male for $\sim 18 \mathrm{~h}$. Each female was presumably mated, because 1-dayold males can mate up to 15 females a day (Krainacker \& Carey, 1988). Mating status was determined by examining sex ratio of offspring; male-only families were assumed to represent non-mated mothers. The presumably mated female mites were transferred onto two-leaf stage bean plants that were grown individually in pots $(10 \mathrm{~cm}$ diameter $)$. The plants were moved from greenhouse to laboratory where conditions were 16:8 $\mathrm{LD}, 29 \pm 1^{\circ} \mathrm{C}$, and $\sim 30$ per cent $\mathrm{RH}$. Leaves were assigned to mites at random, and a small amount of tanglefoot (The Tanglefoot Co., Grand Rapids, Michigan) was applied to the petiole of each leaf to prevent mites from wandering off. Mites were individually reared on the first foliage leaves that provided each full-sib family with adequate space and nutrition for development. Mothers were removed from the leaves 8 days later because the eggs laid on the first day were about to develop into the adult stage, and the majority of eggs had been laid within the first 8 days (Krainacker \& Carey, 1989). Soon after the removal of the mothers, the leaves were cut from the plants and set on top of new leaves rested on wet cotton in trays for offspring collection.

Measurements of aerial dispersal behaviour were made on about six 1-day-old adult female offspring from each full-sib family, because such mites are dominant dispersers (Smitley \& Kennedy, 1985). Aerial dispersal behaviour was defined as a mite raising its front body and forelegs and facing away from the light under test conditions for at least 5-10 s (Smitley \& Kennedy, 1985), and it was measured in latency, i.e. the number of minutes between the start of the test and the display of the behaviour. The test was conducted at about $28^{\circ} \mathrm{C}, 30$ per cent $\mathrm{RH}, 71-73 \mathrm{~cm} / \mathrm{Hg}$ barometric pressure, and under laboratory conditions described by Margolies (1987). Wind at $\sim 1.5 \mathrm{~ms}^{-1}$ was produced by a window fan set $1 \mathrm{~m}$ from the test arena on a table, and a light source was provided by a 100 watt incandescent light bulb set on top of the fan. The test arena was made of a piece of wood $45 \times 11 \times 2 \mathrm{~cm}$ (length $\times$ width $\times$ height) coated with black paint. Then, 26 pieces of plastic slides $\left(2.3 \mathrm{~cm}^{2}\right)$, also coated with black paint, were glued onto the top of the wood in two rows. The slides were arena cells and were isolated by tanglefoot to prevent mites from walking between the cells during a test. Prior to a test, a maximum of six adult female offspring from each full-sib family was collected from the bean leaves and kept on fresh bean leaf discs separated by family. A few hours later, they were transferred onto the arena with one family per 
cell. A test followed immediately after the transfer, and the mites were subjected to test conditions continuously for $4 \mathrm{~h}$, because a preliminary study indicated that most mites would display the behaviour within that time. Each family was tested twice on different days. A mite that showed the behaviour was removed from the arena and kept individually on a bean leaf disc $(1 \mathrm{~cm}$ diameter), and its latency was recorded. Some mites (less than 5 per cent) did not show the behaviour during the test, therefore, they were excluded from any analysis. To measure fecundity and sex ratio, two female offspring from each full-sib family saved from the test on aerial dispersal behaviour were reared on bean plants in a similar manner to their mothers. Their offspring were counted, and sex was determined at maturity.

\section{Estimation of heritability and correlation}

To normalize the data for analysis of variance, aerial dispersal behaviour and fecundity were subjected to square-root transformation, whereas sex ratio, the proportion of female to total offspring, was transformed into an arcsine-square-root scale (Sokal \& Rohlf, 1981; Ott, 1984). All analyses were based on the transformed data, except that means and standard deviations of the three characters were estimated based on the original scale of measurement.

Because our data were unbalanced, i.e. the number of offspring differed among full-sib families and the full-sib families also differed among half-sib families, the SAS GLM procedure (SAS Institute Inc., 1987) was used to perform the analysis of variance of the three characters. The observed variances due to male, female, and offspring were estimated by using Type I mean squares and the coefficients of their expectations from the analysis of variance (as in Becker, 1975). The SAS NESTED procedure can provide the same estimates, but without a significance test of each variance component. The causal components of variance were estimated from the theoretical relationships between genetic variance and observed variance among halfand full-sib families for a haplodiploid system (see Appendix). Although fractions of variable epistatic variations are included in the observed variances (see Table 4, Appendix), they are usually ignored because of difficulties in estimating them (Falconer, 1981). Additive genetic variance, which was the main object of the analysis, can be estimated by $V_{\mathrm{A}}=2 \sigma_{\mathrm{S}}^{2}$. Nonadditive genetic variance plus maternal effect $\left(V_{\mathrm{NA}+\mathrm{M}}\right)$ and residual environmental variance $\left(V_{\mathrm{e}}\right)$ as a single value $\left(V_{\mathrm{NA}+\mathrm{M}}+V_{\mathrm{e}}\right)$ can be estimated by $\sigma_{\mathrm{D}}^{2}+\sigma_{\mathrm{W}}^{2}-\sigma_{\mathrm{S}}^{2}$; however, they cannot be estimated individually, because $2 \sigma_{\mathrm{D}}^{2}-\sigma_{\mathrm{S}}^{2}=V_{\mathrm{D}}+2 V_{\mathrm{M}}$ and $2 \sigma_{\mathrm{W}}^{2}-\sigma_{\mathrm{S}}^{2}=V_{\mathrm{D}}+2 V_{\mathrm{e}}$, respectively, assuming there is no epistatic variance. However, by assuming $V_{\mathrm{D}}=0$, the minimum value of non-additive genetic variance plus maternal effect can be estimated as

$V_{\mathrm{NA}+\mathrm{M} \min }=\sigma_{\mathrm{D}}^{2}-1 / 2 \sigma_{\mathrm{S}}^{2}$

and, by assuming $V_{\mathrm{M}}=0$, the maximum value can be estimated as

$V_{\mathrm{NA}+\mathrm{M} \max }=2 \sigma_{\mathrm{D}}^{2}-\sigma_{\mathrm{S}}^{2}$.

Likewise, when $V_{\mathrm{NA}+\mathrm{M}}$ is maximum the minimum value of residual environmental variance can be estimated as

$V_{\mathrm{e} \min }=\sigma_{\mathrm{W}}^{2}-\sigma_{\mathrm{D}}^{2}$

and, when $V_{\mathrm{NA}+\mathrm{M}}$ is minimum, the maximum value of residual environmental variance can be estimated as

$V_{\mathrm{e} \max }=\sigma_{\mathrm{W}}^{2}-1 / 2 \sigma_{\mathrm{S}}^{2}$,

where $\sigma_{\mathrm{S}}^{2}$ is the observed variance due to male, $\sigma_{\mathrm{D}}^{2}$ is the observed variance due to female, $\sigma_{\mathrm{W}}^{2}$ is the observed variance due to offspring, $V_{\mathrm{A}}$ is additive genetic variance, $V_{\mathrm{D}}$ is dominance genetic variance, $V_{\mathrm{M}}$ is maternal effect including pre- and post-natal influences, $V_{\mathrm{e}}$ is residual environmental variance, $V_{\mathrm{NA}+\mathrm{M}}$ is non-additive genetic variance plus material effect, and subscripts min and max indicate the minimum and maximum values of corresponding variance.

For analysis of covariance, the SAS MEANS procedure was used to estimate the cross products associated with male, female, and offspring between the three characters. The observed covariances due to male, $C O V_{\mathrm{S}}$, female, $C O V_{\mathrm{D}}$ and offspring, $C O V_{\mathrm{w}}$, were estimated by using the cross products determined from the analysis of covariance and the coefficients of mean square expectations from the analysis of variance (Becker, 1975). The same results can be obtained from SAS NESTED procedure without a significance test. Interpretation of the observed covariance components is the same as that of the observed variance components, except using $C O V$ (e.g. $\left.C O V_{\mathrm{A}}\right)$ instead of $V$ (e.g. $\left.V_{\mathrm{A}}\right)($ Becker, 1975).

Heritability in the narrow sense, defined as $V_{\mathrm{A}} / V_{\mathrm{P}}$, was estimated for each trait. Estimations of heritability were based on the analysis of variance (Becker, 1975; Falconer, 1981). Because the data were unbalanced, a sampling variance of $V_{\mathrm{A}} / V_{\mathrm{P}}$ is difficult to estimate without massive algebra (Searle, 1987). Therefore, only point estimates of heritability were given by $h^{2}=V_{\mathrm{A}} / V_{\mathrm{P}}$ (Falconer, 1981). Standard errors of the heritabilities were estimated by an approximation for moderately unbalanced design (Swiger et al., 1964). Significance levels were determined by the probability 
under normal distribution. A non-parametric method, the Jack-knife technique (Efron, 1982), was also used to estimate heritability, providing two separate estimates of the heritabilities. Because heritability of a trait is also a population parameter and its estimation is based on variances due to male and female, the half-sib family is then the basic unit on which the Jack-knife technique is performed. To obtain Jack-knife estimates, a heritability based on all half-sib families, $h_{\text {all }}^{2}$, was first estimated. Then, each half-sib family was omitted once, and a corresponding heritability $h_{\mathrm{i}}^{2}$ (for $i=1,2, \ldots n$ ) was estimated with the remaining $n-1$ half-sib families. A total of $n$ Jack-knife pseudo-values $h_{\mathrm{ji}}^{2}$ were estimated by

$h_{\mathrm{Ji}}^{2}=n\left(h_{\mathrm{afl}}^{2}\right)-(n-1)\left(h_{\mathrm{i}}^{2}\right)$,

where $n$ is 38 half-sib families in this study. The mean and standard deviation of the pseudo-values were the Jack-knife estimates of heritability and its standard error. The Jack-knife estimates are conservative in the sense that the estimated variances are greater than the true variances (Efron, 1982).

Estimation of genetic and phenotypic correlations were based on the analysis of variance and covariance (Becker, 1975; Falconer, 1981), and the standard general formula, $r=C O V_{(\mathrm{X} . \mathrm{Y})} /\left(V A R_{(\mathrm{X})} \times V A R_{(\mathrm{Y})}\right)^{1 / 2}$, was used. For additive genetic correlation estimates $\left(r_{\mathrm{A}}\right)$ and broad sense genetic correlation estimates $\left\langle r_{\mathrm{G}}\right\rangle$, the variances and covariances due to male and female of an appropriate pair of characters were substituted into the formula. Phenotypic correlations $\left(r_{\mathrm{p}}\right)$ were estimated by using phenotypic variances and covariances of appropriate pairs of characters. Because both variance and covariance components were estimated from unbalanced data, we were unable to estimate sampling variances of correlations (Searle, 1987; Riska, 1989), and only point estimations of correlations were made by the standard method. The same results also can be obtained from the SAS NESTED procedure. To have more confidence in the estimates of correlations, two approximate methods also were used. First, the Jack-knife technique as described above was used by applying the formula for genetic correlation estimation instead of that for heritability. Second, Pearson's product-moment correlations were estimated based on weighted half-sib family means, weighted full-sib family means, and individual offspring values. The estimates based on half- or full-sib family means used the variances and covariances between males or among females; therefore, they represent estimates of additive or broad sense genetic correlations (Via, 1984). The estimates based on individual offspring values used the phenotypic variances and covariances, so they represent estimates of phenotypic correlations. The Pearson's product-moment correlation approximation has an advantage over the standard method in that the significance of the correlation estimates can be tested.

\section{Results}

\section{Means and heritability estimates}

An average of 4.1 female mites was successfully mated to each of the 38 males used in this study. From each resulting full-sib family, an average of 5.2 adult female offspring was measured for aerial dispersal behaviour. In the analyses of fecundity and sex ratio, an average of 3.5 full-sib families each with 1.6 adult female offspring was used for each half-sib family. Means and standard deviations of aerial dispersal behaviour, fecundity, and sex ratio are given in Table 1. Heritabilities of the three traits estimated by both the standard method and the Jack-knife technique are also reported. The heritabilities estimated by the two methods agree well for all traits. The heritability of aerial dispersal behaviour is significant, whereas the heritabilities of fecundity and sex ratio are not distinguishable from zero.

\section{Causal components of variances}

Observed variances of the three traits were partitioned into causal components (Table 2). As indicated by the observed variance due to male, $\sigma_{\varsigma}^{2}$, little additive genetic variation was found in fecundity $(F=1.20$; d.f. $=37,96 ; P=0.2333)$ or sex ratio $(F=0.82$; d.f. $=37,96 ; P=0.7483)$. In aerial dispersal behaviour, both additive genetic variance $(F=2.25$; d.f. $=37,117$; $P=0.0006)$ and non-additive genetic variance plus maternal effect $(F=2.69$; d.f. $=117,650 ; P=0.0001)$ were significantly greater than zero, as indicated by the observed variance due to male, $\sigma_{S}^{2}$, and female, $\sigma_{\mathrm{D}}^{2}$. The two causal components $\left(V_{\mathrm{A}}\right.$ and $\left.V_{\mathrm{NA}+\mathrm{M}}\right)$ together comprised about half (39.44-56.49 per cent) of the total phenotypic variance, indicating that aerial dispersal behaviour was greatly influenced by genetic factors. Non-additive genetic variance plus maternal effect in fecundity $(F=2.18$; d.f. $=96,81 ; P=0.0002)$ or sex ratio $(F=2.41$; d.f. $=96,81 ; P=0.0001)$ was significantly greater than zero and was the major component of the total phenotypic variance. Residual environmental variance may comprise as much as about half of the phenotypic variance in the three traits.

\section{Genetic and phenotypic correlations}

Table 3 presents genetic and phenotypic correlations and standard errors estimated by the standard method, 
Table 1 Aerial dispersal behaviour, fecundity and sex ratio: observations and heritabilities

\begin{tabular}{|c|c|c|c|c|c|c|c|}
\hline Character & Mean & s.d. & $n$ & Method & $h^{2}$ & S.E. & $P$ \\
\hline $\mathrm{ADB} \min$ & 84 & 51 & 805 & Standard & 0.2239 & 0.0651 & 0.0006 \\
\hline \multirow[t]{2}{*}{ Fecundity count } & \multirow[t]{2}{*}{71} & \multirow[t]{2}{*}{22} & \multirow[t]{2}{*}{215} & Standard & 0.0534 & 0.0992 & 0.3096 \\
\hline & & & & Jackknife & 0.0571 & 0.1198 & 0.6362 \\
\hline $\begin{array}{l}\text { Sex ratio } \\
\quad \text { (Proportion female) }\end{array}$ & 0.75 & 0.15 & 215 & Standard & -0.0894 & 0.0751 & 0.3930 \\
\hline
\end{tabular}

$\mathrm{ADB}=$ aerial dispersal behaviour.

$h^{2}$ and S.E. $=$ estimated by standard method and Jackknife technique with associated probability of significance $P$.

Table 2 Observed variance and causal components of aerial dispersal behaviour, fecundity and sex ratio estimated from analysis of variance

Observed

components

Causal components

\begin{tabular}{llll}
\hline & \multicolumn{2}{c}{ Estimated values with proportion $(\%)$} \\
\hline Aerial dispersal behaviour & & Minimum & Maximum \\
$\sigma_{\mathrm{S}}^{2}=0.8696$ & $V_{\mathrm{A}}$ & $1.7392(22.39)$ & $1.7392(22.39)$ \\
$\sigma_{\mathrm{D}}^{2}=1.7594$ & $V_{\mathrm{NA}+\mathrm{M}}$ & $1.3246(17.05)$ & $2.6492(34.10)$ \\
$\sigma_{\mathrm{W}}^{2}=5.1393$ & $V_{\mathrm{e}}$ & $3.3799(43.51)$ & $4.7045(60.06)$
\end{tabular}

$\sigma_{\mathrm{T}}^{2}=7.7683$

Fecundity

$\sigma_{\mathrm{S}}^{2}=0.0520$
$\sigma_{\mathrm{D}}^{2}=0.8146$
$\sigma_{\mathrm{W}}^{2}=1.0815$
$\sigma_{\mathrm{T}}^{2}=1.9481$

$V_{\mathrm{A}} \quad 0.1040(5.34)$

$0.1040(5.34)$

$V_{\mathrm{NA}+\mathrm{M}}$

$0.7886(40.48)$

$1.5772(80.96)$

$V_{\mathrm{e}} \quad 0.2669(13.70)$

$1.0555(54.18)$

Sex ratio

$\sigma_{\mathrm{S}}^{2}=-0.0014$
$\sigma_{\mathrm{D}}^{2}=0.0156$
$\sigma_{\mathrm{W}}^{2}=0.0174$
$\sigma_{\mathrm{T}}^{2}=0.0314$

$V_{\mathrm{A}} \quad-0.0028(0.00)$

$-0.0028(0.00)$

$V_{\mathrm{NA}+\mathrm{M}}$

$0.0163(47.74)$

$0.0326(94.77)$

$V_{\mathrm{e}} \quad 0.0018(5.23)$

$0.0181(52.26)$

Causal components were estimated by means described in the Materials and methods.

$\sigma_{\mathrm{S}}^{2}=$ observed variance due to male; $\sigma_{\mathrm{D}}^{2}=$ observed variance due to female;

$\sigma_{\mathrm{W}}^{2}=$ observed variance associated with offspring; $\sigma_{\mathrm{T}}^{2}=$ phenotypic variance.

$V_{\mathrm{A}}=$ additive genetic variance; $V_{\mathrm{NA}+\mathrm{M}}=$ nonadditive genetic variance plus maternal effect; $V_{\mathrm{e}}=$ residual environmental vasriance. Both minimum and maximum values of $V_{\mathrm{NA}+\mathrm{M}}$ and $V_{\mathrm{e}}$ are given. Minimum $V_{\mathrm{NA}+\mathrm{M}}$ and maximum $V_{\mathrm{e}}$, or vice versa, have to be chosen to reach total phenotypic variance with $V_{\mathrm{A}}$.

the Jack-knife technique, and approximation by Pearson's product-moment correlation on half-sib family means, full-sib family means, and individual offspring values. Correlations estimated by all three methods agree reasonably well, although the Jack-knife technique tends to give larger standard errors. Because the estimate of observed variance in sex ratio due to male, $\sigma_{S}^{2}$, was negative (Table 2), the additive genetic correlations between aerial dispersal behaviour and sex ratio and between fecundity and sex ratio cannot be 
Table 3 Additive genetic correlation $\left(r_{\mathrm{A}}\right)$, broad sense genetic correlation $\left(r_{\mathrm{G}}\right)$ and phenotypic correlations $\left(r_{\mathrm{p}}\right)$ and standard errors between aerial dispersal behaviour, fecundity and sex ratio estimated by the standard method, the Jackknife technique, and correlation on 38 half-sib family means, 134 full-sib family means, and on pooled data of 215 for phenotypic correlation with associated probability of significance $(P)$

\begin{tabular}{|c|c|c|c|c|c|c|c|c|c|c|}
\hline Character & Method & $r_{\mathrm{A}}$ & (s.E.) & $P$ & $r_{\mathrm{G}}$ & (s.E.) & $P$ & $r_{\mathrm{P}}$ & (s.E.) & $P$ \\
\hline $\mathrm{ADB} \times \mathrm{FEC}$ & $\begin{array}{l}\text { Standard } \\
\text { Jackknife } \\
\text { Approximate }\end{array}$ & $\begin{array}{l}-0.9656 \\
-0.4654 \\
-0.2142\end{array}$ & $(1.1259)$ & $\begin{array}{l}0.6818 \\
0.1967\end{array}$ & $\begin{array}{r}0.0706 \\
0.0524 \\
-0.0680\end{array}$ & $(0.2286)$ & $\begin{array}{l}0.8201 \\
0.4348\end{array}$ & $\begin{array}{l}-0.0621 \\
-0.0619 \\
-0.0607\end{array}$ & $(0.0887)$ & $\begin{array}{l}0.4897 \\
0.3756\end{array}$ \\
\hline $\mathrm{ADB} \times \mathrm{SR}$ & $\begin{array}{l}\text { Standard } \\
\text { Jackknife } \\
\text { Approximate }\end{array}$ & $\begin{array}{l}- \\
- \\
0.0107\end{array}$ & & 0.9492 & $\begin{array}{l}-0.2559 \\
-0.1927 \\
-0.0715\end{array}$ & $(0.2143)$ & $\begin{array}{l}0.3757 \\
0.4116\end{array}$ & $\begin{array}{l}-0.0488 \\
-0.0549 \\
-0.0493\end{array}$ & $(0.0965)$ & $\begin{array}{l}0.5728 \\
0.4718\end{array}$ \\
\hline $\mathrm{FEC} \times \mathrm{SR}$ & $\begin{array}{l}\text { Standard } \\
\text { Jackknife } \\
\text { Approximate }\end{array}$ & $\begin{array}{l}\overline{-}_{0.0269} \\
{ }_{0.02}\end{array}$ & & 0.8726 & $\begin{array}{r}-0.0490 \\
0.0507 \\
0.0505\end{array}$ & $(0.3746)$ & $\begin{array}{l}0.8930 \\
0.5624\end{array}$ & $\begin{array}{l}0.0815 \\
0.0856 \\
0.0818\end{array}$ & $(0.0999)$ & $\begin{array}{l}0.3968 \\
0.2321\end{array}$ \\
\hline
\end{tabular}

$\mathrm{ADB}=$ aerial dispersal behaviour; $\mathrm{FEC}=$ fecundity; $\mathrm{SR}=$ sex ratio.

estimated by either the standard method or the Jackknife technique, but they can be approximated by estimating Pearson's product-moment correlation on half-sib family means. The additive genetic correlations between the three characters are not significantly different from zero by any of the three estimations. Neither broad sense genetic correlation nor phenotypic correlation between the three characters is significant.

\section{Discussion}

Heritability and genetic correlation analysis can predict the response of given traits to short-term selection, identify functionally integrated traits and, therefore, provide insight into the nature of genetic constraints on the response (Endler, 1986; Clark, 1987; Maynard Smith, 1989). Because variance-covariance matrices of given traits are functions of genotypes and environments, their values may change in magnitude and even in sign (for covariance) if measured in a different environment, at a different development stage (Via, 1984; Kasule, 1991), or at a different population state approaching optimal equilibrium (Price \& Schluter, 1991). Results of quantitative genetic studies are only statistical abstractions without knowledge of associated biological and environmental properties (Scharloo, 1987; Riska, 1989). Therefore, they must be interpreted in an ecological context, because the organism's environment determines the selective regime under which even the variance-covariance matrix itself may be subject to selection (Travis et al., 1987; Dingle, 1991). Because the sample size in our study was relatively small, i.e. only 38 half-sib families, and our mite population may have undergone adaptation to laboratory conditions during the maintenance of $\sim 9$ months prior to this study, interpretation of the results should be cautious, even though genetic parameters were estimated by two or three different methods that reached similar conclusions.

The significant heritability of aerial dispersal behaviour in T. urticae found in this study (Table 1) indicates that this behaviour can respond to strong selection imposed by the environment. Crop systems that are subjected to frequent natural and imposed disturbances, such as host senescence, harvesting, and even pest destruction, may impose opposing selection on aerial dispersal behaviour through alternations of good and poor host plant qualities. In an unsuitable environment, such as a heavily infested area, a mite may have a better chance of locating suitable host plants by responding to the unsuitability promptly and, therefore, be favoured by selection over slow responders. However, in a suitable or good environment, such as a newly-colonized plant, early dispersal would not necessarily lead the mite to a better food resource, and the mite would have a greater chance of being lost. Therefore, short latency of the behaviour, or over-sensitivity to infestation, may be selected against. Although crop systems are highly disturbed, environmental stability is likely to last at least several generations for newly colonized mites, and rapid response of the behaviour to direct selection can occur within that time (Li \& Margolies, unpublished data). If our speculation is correct, genetic variation in aerial dispersal behaviour in $T$. urticae may have been maintained by temporal variation of the environment, although dis- 
persal or migration behaviour is thought to be an adiaptive response to spatial variation (Southwood, 1962; Stearns, 1976; Parsons, 1983).

Aerial dispersal behaviour in $T$. urticae may be correlated with morphological, physiological, and life history traits; therefore, additive genetic variation in this behaviour may be maintained by selection of one or some of these traits or on different traits in different phases of selection. However, the fact that our study did not reveal the existence of genetic correlations between aerial dispersal behaviour, fecundity, and sex ratio (Table 3 ) indicates that the existence of additive genetic variation in the behaviour is not a result of correlated selection on the latter traits. This finding, and the rapid response to direct selection ( $\mathrm{Li} \&$ Margolies, unpublished data), suggest that aerial dispersal behaviour may be selected directly by nature through the underlying morphological or physiological traits.

The large amounts of non-additive genetic variation and maternal effect in fecundity and sex ratio (Table 2) significantly reduce the proportion of additive genetic variation in total phenotypic variation. This may account for the lack of heritability in the two traits. Maternal effects on phenotypic variation in insects and other animals have been documented by many researchers (e.g. Falconer, 1965; Janssen et al., 1988; Leamy, 1988). Such effects on life-history traits in $T$. urticae have also been observed; for example, strains and individual females have significant effects on sex ratio (Mitchell, 1972; Young et al., 1986). The significant amount of non-additive genetic variance and common environmental effects in fecundity and sex ratio $(40-80$ per cent) revealed in this study may be partly responsible for the maternal influence on the $T$. urticae sex ratio observed by these researchers.

Because no significant heritability of fecundity and sex ratio was found in this study (Table 1), there appears to be little genetic variance available for direct selection on these two traits; this is typical in life-history traits (Clark, 1987; Rose et al., 1987). Fecundity and sex ratio, like other life-history traits, are compo-site traits with underlying morphological and/or physiological traits. Large environmental influences associated with such underlying traits may result in their inevitable low genetic values in quantitative genetic studies (Riska, 1989; Price \& Schluter, 1991). In addition, these traits may have been under strong and continuing directional selection which resulted in fixation of genetic variation. The lack of any correlation between sex ratio and aerial dispersal or fecundity and aerial dispersal suggests that indirect selection will not affect sex ratio or fecundity either. Our results agree with previous studies that indicate heritability and genetic correlation of life-history and behavioural traits are generally smaller than those of morphological traits (see Roff \& Mousseau, 1987).

In nature, non-additive genetic variance and common environmental effects on fecundity, sex ratio, and aerial dispersal behaviour in $T$. urticae may have an even greater effect than we observed in a controlled environment. The two-spotted spider mite is an aggregated species (Broudreaux, 1963; Mitchell, 1973) in which individuals, usually relatives, tend to feed in groups and leave the feeding site only after a food resource has been exhausted. In the early stages of colonization, most dispersed individuals are likely to live with their offspring. Their eggs are produced in a confined area on host leaves, and immatures usually develop in that area (Mitchell, 1973). Therefore, the pattern of eggs being produced may determine the microenvironment in which the immatures develop and, in turn, affect every individual in the family. For example, population density has significant negative effects on mite developmental rate, survivorship, sex ratio, fecundity, and body size at maturity (Mitchell, 1973; van Impe, 1984). Clearly, knowledge of mite field ecology is essential to fully understanding its quantitative genetics and adaptation to its environment.

\section{Acknowledgements}

We thank J. Meyer, North Carolina State University, for providing the mite population; B. Black, S. Cox and J. Nechols for helpful comments on an earlier draft; and M. Wade, University of Chicago, for statistical advice. This work was supported by USDA-CRGO Grant No. 88-37234-3499 to D.C.M. Contribution No. 92-612-J from the Kansas Agricultural Experiment Station, Kansas State University, Manhattan, KS.

\section{References}

BECKER, W. A. 1975. Manual of Quantitative Genetics. Washington St University Press, Pullman, WA. pp. 51-52; $106-107$

BRoUdreauX, H. B. 1963. Biological aspects of some phytophagous mites. Ann. Rev. Entomol., 8, 137-154.

CIIARnov, E. L. 1989. Phenotypic evolution under Fisher's fundamental theorem of natural selection. Heredity, $\mathbf{6 2}$, $113-116$

Cl.ARK, A. G. 1987. Genetic correlations: the quantitative genetics of evolutionary constraints. In: Loeschccke, V. (ed.) Genetic Constraints on Adaptive Evolution. SpringerVerlag, Berlin, pp. 25-45.

DINGI.E, H. 1991. Evolutionary genetics of animal migration. Am. Zool., 31, 253-264.

EFRON. B. 1982. The Jackknife, the Bootstrap and Other Resampling Plans. Society for Industrial and Applied Mathematics, Philadelphia, PA. 
ENDler, J. A. 1986. Natural Selection in the Wild. Princeton University Press, Princeton, NJ.

FALCONER, D. S. 1965. Maternal effects and selection response. In: Geerts, S. J. (ed.) Genetics Today, Proc. XI Internat. Congr. Genetics, vol. 3, Pergamon Press, Oxford, pp. 763-774.

FALCONER, D. S. 1981. Introduction to Quantitative Genetics, 2nd edn. Longman Press, London.

GU, H. AND DANTHANARAYANA, w. 1992. Quantitative genetic analysis of dispersal in Epiphyas postvittana. II. Genetic covariations between flight capacity and life-history traits. Heredity, 68, 61-69.

HELLE, w. 1967. Fertilization in the two-spotted spider mite (Tetranychus urticae: Acari). Entomol. Exp. Appl., 10, 103-110.

HOULE, D. 1991. Genetic covariance of fitness correlates: what genetic correlations are made of and why it matters. Evolution, 45, 630-648.

HOULE, D. 1992. Comparing evolvability and variability of quantitative traits. Genetics, 130, 195-204.

JANSSEN, G. M., DE LONG, G., JOOSE, E. N. G. AND SCHARLOO, W. 1988. A negative maternal effect in springtails. Evolution, 42, 828-834.

JEPPSON, L. R., KEIFER, H. H. AND BAKER, E. W. 1975. Mites Injurious to Economic Plants. University California Press, Berkeley, CA.

KASULE, F. K. 1991. Associations of fecundity with adult size in the cotton stainer bug Dysdercus fasciatus. Heredity, 66, 281-286.

KRAINACKER, D. A. AND CAREY, J. R. 1988. Maternal heterogeneity in primary sex-ratio of three tetranychid mites. Exp. Appl. Acarol., 5, 151-162.

KRAINACKER, D. A. AND CAREY, J. R. 1989. Reproductive limits and heterogeneity of male twospotted spider mites. Entomol. Exp. Appl., 50, 209-214.

KRAINACKER, D. A. AND CAREY, J. R. 1990. Male demographic constraints to extreme sex ratio in the twospotted spider mite. Oecologia, 82, 417-423.

LANDE, R. 1982. A quantitative genetic theory of life history evolution. Ecology, 63, 607-615.

LEAMY, L. 1988. Genetic and maternal influences on brain and body size in random bred house mice. Evolution, 42, 42-53.

MARGolies, D. C. 1987. Conditions eliciting aerial dispersal behavior in Banks grass mite, Oligonychus pratensis (Acari: Tetranychidae). Environ. Entomol., 16, 928-932.

MARGOLIES, D. C. AND COX, T. S. 1992. Quantitative genetics applied to haplodiploid insects and mites. In: Wrensch, D. L. and Ebbert, M. (eds) Evolution and Diversity of Sex Ratio in Haplodiploid Insects and Mites, Chapman and Hall, New York, pp. 548-559.

MAYNARD SMJTH, J. 1989. Phenotypic models of evolution. In: Hill, W. G. and Mackay, T. F. C. (eds) Evolution and Animal Breeding. C. A. B. International, pp. 67-73.

MITCHELl, R. 1972. The sex ratio of the spider mite Tetranychus urticae. Entomol. Exp. Appl., 15, 299-304.

MITCHELl, R. 1973. Growth and population dynamics of a spider mite (Tetranychus urticae K., Acarina: Tetranychidae). Ecology, 54, 1349 1355.
OTT, L. 1984. An Introduction to Statistical Methods and Data Analysis, 2nd edn. Duxbury Press, Boston.

PALMER, J. O. AND DINGLE, H. 1986. Direct and correlated responses to selection among life-history traits in milkweed bugs (Oncopeltus fasciatus). Evolution, 40, 767-777.

PARSONS, P. A. 1983. The Evolutionary Biology of Colonizing Species. Cambridge University Press, Cambridge.

PRICE, T. AND SCHLUTER, D. 1991. On the low heritability of lifehistory traits. Evolution, 45, 853-861.

RISKA, B. 1989. Composite traits, selection response, and evolution. Evolution, 43, 1172-1191.

ROFF, D. A. AND MOUSSEAU, T. A. 1987. Quantitative genetics and fitness: lessons from Drosophila. Heredity, 58, 103-118.

RoSE, M. R. 1982. Antagonistic pleiotropy, dominance, and genetic variation. Heredity, 48, 63-78.

ROSE, M. R. AND CHARLESWORTH, B. 1981. Genetics of life history in Drosophila melanogaster. I. Sib analysis of adult females. Genetics, 97, 173-180.

ROSE, M. R., SERVICE, P. M. AND HUTCHINSON, E. W. 1987. Three approaches to trade-offs in life-history evolution. In: Loeschccke, V. (ed.) Genetic Constraints on Adaptive Evolution. Springer-Verlag, Berlin, pp. 91-105.

SAS INSTITUTE INC. 1987. SAS User's Guide: Statistics. Cary, NC.

SCHARLOO, w. 1987. Constraints in selection response. In: Loeschccke, V. (ed.) Genetic Constraints on Adpative Evolution. Springer-Verlag, Berlin, pp. 125-149.

SEARLE, S. R. 1987. Linear Models for Unbalanced Data. John Wiley and Sons, New York.

SMITLEY, D. R. AND KENNEDY, G. G. 1985. Photo-oriented aerialdispersal behavior of Tetranychus urticae (Acari: Tetranychidae) enhances escape from the leaf surface. Ann. Ent. Soc. Am., 78, 609-614.

SOKAL, R. R. AND ROHLF, F. J. 1981. Biometry, 2nd edn. W. H. Freeman, San Francisco.

SOUTHWOOD, T. R. E. 1962. Migration of terrestrial arthropods in relation to habitat. Biol. Rev., 37, 171-214.

STEARNS, S. C. 1976. Life-history tactics: a review of the ideas. Q. Rev. Biol., 51, 3-49.

SWIGER, L. A., HARVEY, W. R., EVERSON, D. O. AND GREGORY, K. E. 1964. The variance of intraclass correlation involving groups with one observation. Biometrics, 20, 818-826.

TRAVIS, J., EMERSON, S. B. AND BLOUN, M. 1987. A quantitativegenetic analysis of larval life-history traits in Hyla crucifer. Evolution, 41, 145-156.

VAN IMPE, G. 1984. Influence of population density on the duration of immature development in Tetranychus urticae Koch (Acari: Tetranychidae). In: Griffiths, D. A. and Bowman, C. E. (eds) Acarology VI, vol. 1, John Wiley and Sons, New York, pp. 617-621.

VIA, S. 1984. The quantitative genetics of polyphagy in an insect herbivore. II. Genetic correlations in larval performance within and among host plants. Evolution, 38, 896-905.

YOUNG, S. S. Y., WRENSCH, D. L. AND KONGCHUENSIN, M. 1986. Control of sex ratio by female spider mites. Entomol. Exp. Appl., 40, 53-60. 


\section{Appendix}

The between-sire variance, $\sigma_{S}^{2}$, the among-female variance, $\sigma_{\mathrm{D}}^{2}$, and the within-offspring variance, $\sigma_{\mathrm{W}}^{2}$, were equivalent to $C O V_{(\mathrm{HS})}, C O V_{(\mathrm{FS})}-C O V_{(\mathrm{HS})}$, and $V_{\mathrm{P}}-C O V_{\langle\mathrm{FS}\rangle}$, respectively (Falconer, 1981). The generalized covariance of any sort of relatives is:

$$
\begin{aligned}
C O V & =r V_{\mathrm{A}}+u V_{\mathrm{D}}+r^{2} V_{\mathrm{AA}}+r u V_{\mathrm{AD}}+u^{2} V_{\mathrm{DD}} \\
& +r^{3} V_{\mathrm{AAA}}+\ldots
\end{aligned}
$$

In a haplodiploid system, such as the two-spotted spider mite, the coefficients of relationship $r$ and $u$ are a half and 0 for paternal half-sib sisters and threequarters and a half for full-sib sisters, respectively (Margolies \& Cox, 1992). Therefore, interpretation of the observed components of variance in a sib analysis for a haplodiploid system is different from that for a diploid system (Table 4).

Table 4 Observed components of variance, covariance, and causal components of variance in a sib analysis for Tetranychus urticae, a haplodiploid system

\begin{tabular}{lll}
\hline $\begin{array}{l}\text { Observed } \\
\text { component }\end{array}$ & Covariance & Causal components \\
\hline$\sigma_{\mathrm{S}}^{2}$ & $=C O V_{\langle\mathrm{HS}\rangle}$ & $=1 / 2 V_{\mathrm{A}}+1 / 4 V_{\mathrm{AA}}+1 / 8 V_{\mathrm{AAA}}$ \\
$\sigma_{\mathrm{D}}^{2}$ & $=C O V_{\langle\mathrm{FS}\rangle}-C O V_{(\mathrm{HS})}$ & $=1 / 4 V_{\mathrm{A}}+1 / 2 V_{\mathrm{D}}+5 / 16 V_{\mathrm{AA}}+3 / 8 V_{\mathrm{AD}}+1 / 4 V_{\mathrm{DD}}+19 / 64 V_{\mathrm{AAA}}+V_{\mathrm{Ec}}$ \\
$\sigma_{\mathrm{W}}^{2}$ & $=1 / 4 V_{\mathrm{A}}+1 / 2 V_{\mathrm{D}}+7 / 16 V_{\mathrm{AA}}+5 / 8 V_{\mathrm{AD}}+3 / 4 V_{\mathrm{DD}}+37 / 64 V_{\mathrm{AAA}}+V_{\mathrm{Ew}}$ \\
$\sigma_{\mathrm{T}}^{2}$ & $=V_{\mathrm{P}}-C O V_{\langle\mathrm{FS}\rangle}$ & $=V_{\mathrm{A}}+V_{\mathrm{D}}+V_{\mathrm{AA}}+V_{\mathrm{AD}}+V_{\mathrm{DD}}+V_{\mathrm{AAA}}+V_{\mathrm{Ec}}+V_{\mathrm{Ew}}$ \\
$\sigma_{\mathrm{S}}^{2}+\sigma_{\mathrm{D}}^{2}$ & $=\sigma_{\mathrm{S}}^{2}+\Sigma_{\mathrm{D}}^{2}+\sigma_{\mathrm{W}}^{2}=V_{\mathrm{P}}$ & $=3 / 4 V_{\mathrm{A}}+1 / 2 V_{\mathrm{D}}+9 / 16 V_{\mathrm{AA}}+3 / 8 V_{\mathrm{AD}}+1 / 4 V_{\mathrm{DD}}+27 / 64 V_{\mathrm{AAA}}+V_{\mathrm{Ec}}$ \\
\hline
\end{tabular}

Observed components are: $\sigma_{\mathrm{S}}^{2}=$ variation among paternal half-sib families, $\sigma_{\mathrm{D}}^{2}=$ variation among full-sib families nested within males, $\sigma_{\mathrm{W}}^{2}=$ variation within full-sib families, $\sigma_{\mathrm{T}}^{2}=$ total variation.

Causal components are: $V_{\mathrm{A}}=$ additive genetic variance, $V_{\mathrm{D}}=$ dominance genetic variance, $V_{\mathrm{AA}}=$ additive-additive epistatic variance; $V_{\mathrm{AD}}=$ additive-dominance epistatic variance, $V_{\mathrm{DD}}=$ dominance-dominance epistatic variance, $V_{\mathrm{AAA}}=$ additiveadditive-additive epistatic variance, $V_{\mathrm{E}_{\mathrm{c}}}=$ common environmental variance (including maternal effect), $V_{\mathrm{Ew}}=$ residual environmental variance.

Non-additive plus maternal effect $\left(V_{\mathrm{NA}+\mathrm{M}}\right)$ refered to in the text combines $V_{\mathrm{D}}, V_{\mathrm{AA}}, V_{\mathrm{AD}}, V_{\mathrm{DD}}, V_{\mathrm{AAA}}$, and $V_{\mathrm{Ec}}$. Residual environmental variance is referred to as $V_{\mathrm{e}}$ in text. 